\section{Physical approach for prevention and treatment of osteoporosis}

\author{
Abordagem física para prevenção e tratamento de osteoporose
}

Ana Paula Rebucci Lirani-Galvão', Marise Lazaretti-Castro'

\section{SUMMARY}

Osteoporosis and its consequent fractures are a major problem in public health. To complement the conventional pharmacological treatment for this metabolic disease, non-pharmacological treatment options have been developed in the last decades. Several studies demonstrate that physical exercise programs including impact exercises, specific strength training, balance and coordination training may maintain or increase spine and hip bone mineral density as well as decrease the frequency of falls among osteoporotic and osteopenic patients. Furthermore, some physical agents such as vibratory platforms, low intensity electrical stimulation, laser therapy and ultrasound show positive effects on osteoporotic tissue as well. Consequently, while planning treatment for an osteoporotic patient, non-pharmacological management options should be considered and integrated to the conventional treatment in order to maximize its effects and improve the quality of life of these patients. Arq Bras Endocrinol Metab. 2010;54(2):171-8

\section{Keywords}

Physical exercise; osteoporosis; physical agents; bone density; strength training; impact exercise

\section{SUMÁRIO}

A osteoporose e suas consequentes fraturas são um grande problema de saúde pública. Para complementar o tratamento farmacológico convencional para essa doença metabólica, opções não farmacológicas de tratamento têm sido desenvolvidas nas últimas décadas. Vários estudos demonstram que programas de exercício físico que incluem exercícios de impacto, treino de força específico, equilíbrio e coordenação podem manter ou aumentar a densidade mineral óssea de quadril e coluna, bem como reduzir a frequência de quedas em pacientes osteopênicos e osteoporóticos. Além disso, alguns agentes físicos, como plataformas vibratórias, estimulação elétrica de baixa intensidade, laser e ultrassom, causam efeitos positivos no tecido osteoporótico. Consequentemente, ao se planejar o tratamento para um paciente osteoporótico, opções não farmacológicas devem ser consideradas e integradas ao tratamento convencional com o objetivo de maximizar seus efeitos e melhorar a qualidade de vida desses pacientes. Arq Bras Endocrinol Metab. 2010;54(2):171-8

\section{Descritores}

Exercício físico; osteoporose; agentes físicos; densidade óssea; treino de força; exercícios de impacto
1 Disciplina de Endocrinologia, Departamento de Medicina, Escola Paulista de Medicina, Universidade Federal de São Paulo (Unifesp/ EPM), São Paulo, SP, Brasil
Correspondence to: Ana Paula Rebucci Lirani-Galvão Rua Pedro de Toledo, 910 04039-002 - São Paulo, SP, Brasil analirani@fcr.epm.br or analirani@hotmail.com

Received on Nov/13/2009 Accepted on Feb/28/2010

\section{INTRODUCTION}

$\mathrm{O}$ steoporosis is a multifactorial progressive skeletal disorder characterized by reduced bone mass and deterioration of bone microarchitecture, predisposing it to increased fracture risk. These fractures exert a great impact on public health, as they are often associated to increased morbidity, mortality, loss of function and high economic costs which, only in the United States, may reach 15 billion dollars a year (1). Thus, pharmacological and nonpharmacological treatment options have been largely developed in the last two decades in order to enhance bone mineral density (BMD) as well as to reduce the risk of fractures in osteoporotic patients. Non-pharmacological treatment is usually based on physical exercise and rehabilitation designed specifically for osteoporotic patients and on physical agents that could preserve or improve BMD. 


\section{PHYSICAL EXERCISE AND REHABILITATION}

Several investigations have demonstrated the relevance of physical activity to improve or maintain bone mass in all ages. Some recent data have shown that some specific exercises, in the form of short, repetitive and multidirectional mechanical loading, lead to greatest gains in bone strength $(2,3)$. In order for a physical exercise to be called "osteogenic" it must produce an environment of loads which differs from the habitual, and bone formation will only happen if a certain threshold is achieved. This process is influenced by intensity, frequency, amplitude and duration of stimulus intercalated with resting periods (4).

According to Borer (5), these specific exercises for osteoporotic patients should: (i) be dynamic, not static; (ii) exceed a threshold intensity; (iii) exceed a threshold strain frequency; (iv) be relatively brief but intermittent; (v) impose an unusual loading pattern on the bones; (vi) be supported by unlimited nutrient energy; and (vii) include adequate calcium and cholecalciferol (vitamin D) availability. Thus, to achieve these goals, an osteogenic exercise could be basically promoted through impact exercises and strength training.

\section{Impact exercises}

Continuous bone remodeling demonstrates the ability of adaptation of this tissue to resist typical daily workloads (6). Therefore, impact exercises may enhance bone formation, since mechanical loading provides an anabolic stimulus for bone (7). It has been shown recently that mechanical loading can either maintain or increase bone matrix, reducing osteocyte apoptosis, and stimulating osteoblast differentiation, probably mediated by calcium signaling associated to mechano- and voltage-activated channels, second messengers such as nitric oxide as well as Wnt/ $\beta$-catenin, prostaglandin, and other intracellular pathways (6-8). Although the biological processes involved in this osteogenic response are not completely understood, it has been accepted that the osteogenic response to mechanical stress is impaired with aging (9) and that certain exercises can improve this mechano-sensitive apparatus for a more effective bone formation and maintenance (2).

Specific physical training has been shown to preserve or improve bone mass in postmenopausal women with low BMD $(3,10)$. Postmenopausal women, when submitted to an exercise program based on stretching, balance, resistance exercises and impact exercises as- sociated to hormone therapy, show a higher BMD of femoral neck, when compared to women submitted to hormone therapy only (11).

However, to "mechanically stimulate bone" does not necessarily mean to indicate high-impact exercises to all of our patients. In an investigation with adult female athletes, Nikander and cols. (12) demonstrated that high-impact (jumping) and odd-impact (soccer and squash) exercise-loadings appear to have a similar ability to thicken the femoral neck cortex $(\sim 20 \%$ thicker cortex $v s$. sedentary controls). The softer, mechanically less demanding odd-impact exercises might be a better option for many common people than vigorous highimpact exercises, especially for the frail elderly and for the ones at high risk for fractures. Exercise regimens comprising moderate-magnitude impacts from varying odd directions such as ball games, dancing, modified gymnastics and aerobic exercises could be used against hip and spine fragility.

\section{Strength training}

Strength training may also increase mechanical stress on bone promoting osteogenesis (2), and bone piezoelectric effect - which is the capacity of bone to transform mechanical signs into electrical signs - and has been theorized as justifying the maintenance or even the increment of BMD. Through this mechanism, actions like compression, tension or torsion can generate electrical signs which stimulate bone cellular activity and mineral deposition on the stress points caused by muscle contraction (13).

Muscle contraction can increase BMD by stimulating bone formation (13) and, possibly, inhibiting bone reabsorption (14). Strength training exercises and a more active lifestyle may help postmenopausal women to maintain BMD, and osteopenic and osteoporotic women to improve spine and hip BMD (15). In this systematic review, it was cited that BMD increment appears to be site-specific and requires training from $70 \%$ to $90 \%$ of 1 repetition maximum ( $1 \mathrm{RM}$ ), in 8 to 12 repetitions, 2 to 3 sessions per week, in a period of 1 year. One RM is defined as the maximum weight that can be successfully lifted once. In another study with postmenopausal women the training program comprised three resistive exercise sessions per week in the course of 6 months. Participants started the exercise session with a 10-minute warm-up set, followed by one set at $50 \%$ of the $1 \mathrm{RM}$, gradually increased until 
$85 \%$ throughout the program. Each session included strength training of hip flexors, adductors and abductors, elbow flexors and extensors, back extensors and abdominal muscles. The untrained group showed a significant decrease on lumbar spine and femoral neck BMD values, while the trained group maintained bone mass in these areas (16).

Sinaki and cols. (17) evaluated the effects of strength training exercises on extensor lumbar muscles in postmenopausal women, and demonstrated a reduced incidence of vertebral fractures, showing that resistive exercise helps to prevent the loss and/or to maintain bone mass, improving balance and reducing falls, one of the greatest risk factors in this population. Moreover, back-extensor-strengthening exercises can significantly reduce the incidence of new fractures in patients submitted to vertebroplasty (18).

A systematic review of literature has recently shown that exercise effects on bone are site-specific, and influence preferentially cortical rather than trabecular bone (19). In a 12-month investigation, Winters-Stone and Snow (20) demonstrated that women who added upper body resistance exercise to a routine of lower body resistance and jump training increased BMD of both the hip $(+2.2 \%)$ and spine $(+1.3 \%)$. In contrast, women who performed only lower body training increased hip $(+2.6 \%$ vs. $-0.7 \%$ control $)$ but not spine BMD $(+0.3 \%$ vs. $-0.5 \%$ control).

The strength of certain muscles was recently found to correlate with BMD. Monaco and cols. (21) demonstrated that hand grip may correlate with femoral $(\mathrm{r}=0.37, \mathrm{p}<0.01)$, lumbar spine $(\mathrm{r}=0.44, \mathrm{p}<0.01)$ and total body $(\mathrm{r}=0.37, \mathrm{p}<0.01)$ BMDs. Additionally, Lindsey and cols. (22) also associated physical performance measures and BMD in older postmenopausal women. Variables such as static balance and hand grip were associated to total body, lumbar spine, hip, and forearm BMDs. Consequently, it is important to emphasize that these parameters should be considered by clinicians in the assessment of osteoporotic patients.

Apart from that, rapid strength training exercises were shown to promote even better results when compared to conventional resistive exercises. Resistance exercises performed in a very dynamic way (resistance + velocity $=$ power training) with high loads and few repetitions involve vigorous muscle contractions and demand type II fiber action, and it seems that these fibers are the most capable of stimulating bone formation (23). Moreover, eccentric muscle training seems to promote larger osteogenic stimulation when compared to concentric muscle action (24).

In this context, Stengel and cols. (25) conducted a randomized trial in which 53 pre-trained women (mean age of 58.2 years) were randomly assigned to a strength training $(\mathrm{ST})$ or power training (PT) group. The difference between the two groups was velocity of the movement during resistance training: ST -4 seconds for concentric and 4 seconds for eccentric contraction; PT - explosive concentric and 4 seconds for eccentric contraction. Otherwise, both groups carried out progressively planned resistance training (10-12 exercises, 2-4 sets, $4-12$ repetitions at $70-92.5 \%$ of the $1 \mathrm{RM}$ (twice a week) for 2 years). After 2 years of training, women submitted to PT lost only $0.3 \%$ of lumbar spine BMD, while ST lost $2.4 \%$. These results led the authors to the conclusion that power training may be superior to maintain BMD in postmenopausal women than strength training. In addition, power training was considered safe as it did not lead to increased injury or pain.

There are still contradictions in literature when it comes to pool-based exercises for osteoporotic patients. Water sports athletes normally show lower BMD compared to other modalities (14). However, these athletes train in the water for 3 to 5 hours a day, 5 to 6 times a week, which is a totally different reality from the aquatic activities proposed to osteoporotic patients in order to maintain health and quality of life.

It is well known that there are significant gains of muscle strength and resistance in subjects submitted to pool-based exercise programs. Cardoso and cols. (26) studied 34 postmenopausal women, who exercised for 12 weeks, twice a week, practicing deep-water exercises with emphasis in muscle strength. Subjects performed movements using lower and upper limbs, from 70\% to $90 \%$ of maximum intensity, with and without resistive equipment. Results demonstrated that both training with bare limbs and with equipment significantly improved muscle strength of subjects in the study, showing that water workouts with emphasis in muscle strength can enhance this neuromuscular variable.

Furthermore, some evidences show that even with reduced articular impact inside the water, it is possible to develop osteogenic potential through specific muscle strength training in the aquatic environment. Ay and Yurtkuran (27) found an anabolic effect of pool-based exercises on bone of postmenopausal women which was evidenced by increased hormonal markers (insulin-like growth factor-1, growth hormone and calcitonin) and 
calcaneous ultrasound measurements. However, more clinical trials should be performed in order to clarify if these pool-based exercises can maintain or increase BMD in osteoporotic patients.

\section{Strength training vs, impact exercises}

Some authors claim that strength training is more effective in increasing or maintaining BMD when compared to impact exercises such as running, an already known osteogenic enhancer, especially in anatomical sites where both activities produce mechanical stress, such as on the femur neck (28), but the association of both types of training is usually cited as the best option. In a recent meta-analysis, it was found that the most consistent positive changes on BMD after an exercise program were at the lumbar spine following high intensity resistance training. In most of the studies cited, a consistent significant increase was evident in lumbar spine BMD but not femoral neck or total hip. Therefore it was concluded that regular high intensity resistance training appears to be an appropriate exercise therapy in maintaining lumbar spine BMD among postmenopausal women, although the inclusion of other weightbearing activities may also be necessary to best augment hip BMD without other therapeutic agents (29).

Intense and high impact exercise associated to strength training may improve BMD (of lumbar spine and hip) and reduce back pain and lipid levels in osteopenic women in their critical, early postmenopausal years. In this study, the 26-month protocol was performed in 4 sixty-minute sections per week and included warm-up, a jumping sequence, a high-intensity strength training sequence (especially for muscles adjacent to the trunk and proximal femur) and flexibility training. Following the protocol, DXA showed a $2.3 \%$ decrease in spine BMD in the control group, whereas the same parameter in the exercise group was stable (30).

\section{Physical exercise program for osteoporotic patients}

It is important to mention that an appropriate physical exercise program for an osteoporotic patient should focus not only on bone mass. In addition to low BMD, patients at risk for osteoporotic fractures experience several risk factors for falls. Sensory deficits, living alone, advanced age, musculoskeletal weakness, diminished reflexes and coordination, concomitant medications, and associated diseases may contribute to a propensity for falls in this population. Elders who have fallen previously are at risk for future falls due to lack of confidence and potentially uncorrected environmental hazards (31).

According to the recommendations of the American College of Sports Medicine (9), a program of physical exercises for osteoporotic people should include: strength exercises, weight bearing and impact exercises, flexibility, coordination and balance activities and cardiovascular conditioning. These factors are important because they contribute directly to a better quality of life for osteoporotic patients, decreasing the risk of falls and providing them with the opportunity of having a more active life style, therefore avoiding, greater bone loss caused by inactivity. These recommendations indicate that not only highly osteogenic exercises (e.g. strength training and running) are indicated in the treatment and prevention of osteoporosis. The development of balance and coordination leads the subject to have more body consciousness, with a reduced fall risk. Aerobic exercises also benefit osteoporotic patients by giving them more determination for daily activities, allowing them to develop the habit of a more active lifestyle.

Gunendi and cols. (32) showed that a 4-week submaximal aerobic exercise program (on a treadmill for 30 minutes twice a week) provided significant improvements in static and dynamic balances in postmenopausal osteoporotic women.

Specific workstation exercises can significantly improve balance and muscle strength (hip adductors, abductors and quadriceps) in osteopenic women. In this investigation, the exercises were performed in two onehour exercise sessions per week for 20 weeks conducted by a trained physiotherapist and included functional strength activities, flexibility, balance strategy practice, sensory integration, added attention demands during function, multi-task practice, trunk stability training and/or multidirectional skeletal loading (33).

Another option to be included in the exercise program is Tai Chi, an intervention that combines deep breathing and relaxation with slow and gentle exercises, which could possibly have beneficial effects on balance, preventing falls and fractures. A randomized, prospective study concluded that Tai Chi is beneficial for retarding bone loss, which ultimately may help to reduce fracture risk (34). On the other hand, Lee and cols. (35), in a systematic review showed that most of the studies with postmenopausal women and elderly patients failed to show specific effects of Tai Chi on 
BMD. However, Tai Chi may play an important role in the prevention of osteoporotic fractures because it can improve balance, muscle strength and prevent falls (36) (Table 1).

Table 1. Effects of physical exercise programs on bone

\begin{tabular}{|c|c|c|}
\hline $\begin{array}{l}\text { Subjects and } \\
\text { Reference }\end{array}$ & $\begin{array}{c}\text { Physical exercise } \\
\text { program }\end{array}$ & $\begin{array}{c}\text { Effects on bone and } \\
\text { other effects }\end{array}$ \\
\hline $\begin{array}{l}\text { Postmenopausal } \\
\text { women (11) }\end{array}$ & $\begin{array}{l}\text { Stretching + balance + } \\
\text { resistance exercises + } \\
\text { impact exercises + hormone } \\
\text { therapy }\end{array}$ & $\begin{array}{c}\uparrow \text { Femoral neck BMD } \\
\text { (vs. only hormone therapy) }\end{array}$ \\
\hline $\begin{array}{l}\text { Postmenopausal } \\
\text { women (16) }\end{array}$ & $\begin{array}{l}\text { Strength training (hip } \\
\text { flexors, adductors, } \\
\text { abductors, elbow flexors } \\
\text { and extensors, back } \\
\text { extensors, abdominal } \\
\text { muscles) }\end{array}$ & $\begin{array}{l}\text { Maintenance of lumbar } \\
\text { spine and femoral neck } \\
\text { BMD }\end{array}$ \\
\hline $\begin{array}{l}\text { Postmenopausal } \\
\text { women (17) }\end{array}$ & $\begin{array}{l}\text { Strength training (extensor } \\
\text { lumbar muscles) }\end{array}$ & $\begin{array}{l}\text { Maintenance of lumbar } \\
\text { spine BMD } \\
\downarrow \text { Incidence of vertebral } \\
\text { fractures }\end{array}$ \\
\hline $\begin{array}{l}\text { Premenopausal } \\
\text { women }(20)\end{array}$ & $\begin{array}{l}\text { Upper and lower body } \\
\text { resistance exercise + jump } \\
\text { training }\end{array}$ & $\uparrow$ Hip and spine BMD \\
\hline $\begin{array}{l}\text { Postmenopausal } \\
\text { women (27) }\end{array}$ & Pool-based exercises & $\begin{array}{c}\uparrow \text { Hormonal markers } \\
\text { (insulin-like growth } \\
\text { factor- } 1 \text {, growth hormone } \\
\text { and calcitonin) } \\
\uparrow \text { Calcaneous ultrasound } \\
\text { measurements }\end{array}$ \\
\hline $\begin{array}{l}\text { Postmenopausal } \\
\text { women (30) }\end{array}$ & $\begin{array}{l}\text { High impact exercise + } \\
\text { strength training } \\
\text { (trunk and proximal femur } \\
\text { muscles) }\end{array}$ & $\begin{array}{c}\uparrow \text { Lumbar spine and hip } \\
\text { BMD } \\
\downarrow \text { Back pain }\end{array}$ \\
\hline $\begin{array}{l}\text { People aged } \\
\geq 60(36)\end{array}$ & Tai Chi & $\begin{array}{l}\text { Prevention of falls } \\
\uparrow \text { Balance } \\
\uparrow \text { Muscle strength }\end{array}$ \\
\hline
\end{tabular}

In addition to the recognized relevance of physical activity on bone health, it is extremely important to perform exercises carefully and safely in order to avoid muscular pain, inadequate posture and fractures in places that are more fragile due to osteoporosis. It is recommended to avoid movements with greater stress potential to the spine such as spine flexion, rotation and lateral flexion as well as to carry weight inadequately. Concerning these precautions, Sinaki and Mikkelsen (37) demonstrated that there is a greater incidence of compression vertebral fractures in osteoporotic patients who perform trunk flexion during training.

Consequently, bearing in mind the safety measures of prescribing an individually designed exercise program, osteoporotic patients greatly benefit from physi- cal exercise. Exercises with rapid and slow alternate movements, impact exercises (e.g., jogging), aerobic exercises (which exceed $70 \%$ of cardiac frequency), and strength training programs that involve important muscle groups and displacement in various directions, should be used with the aim of reducing bone loss and frequency of falls $(8)$.

\section{PHYSICAL AGENTS}

Since Fukada and Yasuda (38) described bone piezoelectricity, several forms of treatment have been suggested based on this property of bone to transform mechanical energy into electrical energy. The osteogenic potential of mechanical signs on bone can be easily evidenced through impact physical activity, largely cited as one of the main stimulus for bone formation (39) as well as the use of vibratory platforms to prevent and/ or reduce bone mass loss (40).

Sehmisch and cols. (41) showed that whole-body vertical vibration may improve BMD and biomechanical properties of vertebrae of OVX rats after 35 days of treatment. A 1-year prospective, randomized, doubleblind, and placebo-controlled trial of postmenopausal women demonstrated that 20 minutes of a low-level vibration applied during quiet standing can effectively inhibit bone loss in the spine and femur. Placebo subjects lost $2.13 \%$ in the femoral neck over 1 year, whereas treatment was associated with a gain of $0.04 \%$, reflecting a $2.17 \%$ relative benefit of treatment. In the spine, the $1.6 \%$ decrease observed over 1 year in the placebo group was reduced to a $0.10 \%$ loss in the active group, indicating a $1.5 \%$ relative benefit of treatment (40).

Another form of mechanical stimulation on bone, low intensity pulsed ultrasound (LIPUS), was developed by Duarte (42) to accelerate fracture consolidation and has been shown to accelerate bone nodule formation and enhance alkaline phosphatase activity in human osteoblast lineage (NHOst), and increase trabecular spongiosa of femurs in ovariectomized (OVX) rats (43). LIPUS was approved by the FDA (Food and Drug Administration) (44) to promote bone repair and has been used clinically for this purpose. In clinical randomized trials, it has been shown that LIPUS can considerably reduce the time to normal fracture repair (45). In addition to its clear effect on bone repair, LIPUS application is restricted to small body regions, what has limited its use for a systemic metabolic bone disease such as osteoporosis. 
Electrical stimulation for bone repair has also been successfully used in clinical cases of non-unions (46), vertebral fusion (47) and had the approval of the FDA (44) for bone repair as well. Moreover, we showed recently that low intensity electrical stimulation may counteract the effects of OVX on BMD (48), nitric oxide synthase expression, osteocyte viability, bone structure and microarchitecture in rats (49).

Similarly, it was demonstrated recently that pulsed electromagnetic fields (PEMF) could prevent osteoporosis in ovariectomized rats suppressing trabecular bone loss (50). Tabrah and cols. (51) tested a PEMF on the arm of osteoporotic women for 3 months and observed significatively higher values of radius BMD. In a double-blind randomized study, 40 postmenopausal women were exposed to a PEMF $(\mathrm{n}=20)$ or placebo $(\mathrm{n}=$ 20) for lhour/day, 3 times a week for 3 months (spine and pelvis were exposed to the field). In the treated group there was a significant augmentation on osteocalcin and amino-terminal procollagen propeptides of type I collagen serum levels, which are bone formation markers, but there was no significant variation of BMD which could be attributed to the short period of time of treatment (52).

More recently, another physical agent that has been studied is low level laser therapy (LLLT), which shows stimulatory effects on osteoblast-like cells, increasing its viability (53), DNA and RNA synthesis, bone nodule formation (54) as well as alkaline phosphatase activity and expressions of osteopontin and collagen type I mRNA (53). LLLT may accelerate the process of fracture repair in rabbit tibial fracture by increasing callus volume and BMD, especially in the early stages of bone remodeling (55). LLLT may also have a positive effect on osteogenesis in osteopenic rats, increasing bone strength, calcium content and BMD of the treated femoral area (56). Moreover, Diniz and cols. (57) demonstrated that the association of bisphosphonate and LLLT is able to increase trabecular bone volume in vertebrae of osteopenic rats in an additive manner. Nevertheless, LLLT is a punctual laser shot, what limits its application in whole body to test its efficacy in the prevention of osteoporosis.

\section{CONCLUSION}

It is very well documented that physical stimulus can affect skeletal resistance due to the ability of bone tissue to transform mechanical load in electrical energy that can be transmitted into bone cells and interferes on their metabolism (58). In the same way, disuse is probably the fastest way to lose bone. So, physical exercise plays an important role in the prevention of osteoporosis and it is always recommended as coadjuvant in the treatment of installed osteoporosis. Thanks to bone tissue piezoelectricity it is possible to use other physical methods such as mechanical vibration, ultrasound or electrical field to stimulate bone formation, and these techniques are being developed with the aim of giving us future alternatives to optimize the prevention and treatment of osteoporosis.

Acknowledgments: Conselho Nacional de Desenvolvimento Científico e Tecnológico $(\mathrm{CNPq})$ for financial support.

Disclosure: no potential conflict of interest relevant to this article was reported.

\section{REFERENCES}

1. NIH Consensus Development Panel on Osteoporosis Prevention, Diagnosis and Therapy. Osteoporosis prevention, diagnosis and therapy. J Am Med Assoc. 2001;285:785-95.

2. Turner $\mathrm{CH}$, Robling $\mathrm{AG}$. Mechanisms by which exercise improves bone strength. J Bone Miner Metab. 2005;23 Suppl:16-22.

3. Bergström I, Landgren BM, Brinck J, Freyschuss B. Physical training preserves bone mineral density in postmenopausal women with forearm fractures and low bone mineral density. Osteoporosis Int. 2008;19(2):177-83.

4. Bono CM, Einhorn TA. Overview of osteoporosis: pathophysiology and determinants of bone strength. Eur Spine J. 2003;12(Suppl 2):S90-6.

5. Borer KT. Physical activity in the prevention and amelioration of osteoporosis in women: interaction of mechanical, hormonal and dietary factors. Sports Med. 2005;35(9):779-830.

6. Bonewald LF, Johnson ML. Osteocytes, mechanosensing and Wnt signaling. Bone. 2008;42(4):606-15.

7. Turner $\mathrm{CH}$, Robling $\mathrm{AG}$. Exercise as an anabolic stimulus for bone. Curr Pharm Des. 2004;10(21):2629-41.

8. Bloomfield SA. Optimizing bone health: impact of nutrition, exercise, and hormones. Sports Sci Exchange. 2001;14(3):1-6.

9. Kohrt WM, Bloomfield SA, Little KD, Nelson ME, Yingling VR. American College of Sports Medicine Position Stand: physical activity and bone health. Med Sci Sports Exerc. 2004;36(11):1985-96.

10. Kemmler W, Engelke K, Lauber D, Weineck J, Hensen J, Kalender WA. Exercise effects on fitness and bone mineral density in early postmenopausal women: 1-year EFOPS results. Med Sci Sports Exerc. 2002;34:2115-23.

11. Going S, Lohman T, Houtkooper L, Metcalfe L, Flint-Wagner H, Blew $R$, et al. Effects of exercise on bone mineral density in calcium-replete postmenopausal women with and without hormone replacement therapy. Osteoporos Int. 2003;14:637-43.

12. Nikander R, Kannus P, Dastidar P, Hannula M, Harrison L, Cervinka $\mathrm{T}$, et al. Targeted exercises against hip fragility. Osteoporos Int. 2009;20(8):1321-8.

13. Menkes A, Mazel S, Redmond RA, Koffler K, Libanati CR, Gundberg $\mathrm{CM}$, et al. Strength training increases regional bone mineral 
density and bone remodeling in middle-aged and older men. $\mathrm{J}$ Appl Physiol. 1993;74(5):2478-84.

14. Andreoli A, Monteleone M, Van Loan M, Promenzio L, Tarantino U, De Lorenzo A. Effects of different sports on bone density and muscle mass in highly trained athletes. Med Sci Sports Exerc. 2001;33(4):507-11.

15. Zehnacker $\mathrm{CH}$, Bemis-Dougherty A. Effect of weighted exercises on bone mineral density in post menopausal women a systematic review. J Geriatr Phys Ther. 2007;30(2):79-88.

16. Bocalini DS, Serra AJ, dos Santos L, Murad N, Levy RF. Strength training preserves the bone mineral density of postmenopausal women without hormone replacement therapy. J Aging Health. 2009;21(3):519-27.

17. Sinaki $\mathrm{M}$, Itoi $\mathrm{E}$, Wahner HW, Wollan $\mathrm{P}$, Gelzcer $\mathrm{R}$, Mullan $\mathrm{BP}$, et al. Stronger back muscles reduce the incidence of vertebral fractures: A prospective 10 year follow-up of postmenopausal women. Bone. 2002;6:836-41.

18. Huntoon EA, Schmidt CK, Sinaki M. Significantly fewer refractures after vertebroplasty in patients who engage in back-extensorstrengthening exercises. Mayo Clin Proc. 2008;83(1):54-7.

19. Hamilton CJ, Swan VJ, Jamal SA. The effects of exercise and physical activity participation on bone mass and geometry in postmenopausal women: a systematic review of pQCT studies. Osteoporos Int. 2010;21(1):11-23.

20. Winters-Stone KM, Snow CM. Site-specific response of bone to exercise in premenopausal women. Bone. 2006;39(6):1203-9.

21. Monaco MDI, Monaco RDI, Manca M, Cavanna A. Handgrip strength is a independent predictor of distal radius bone mineral density in postmenopausal women. Clin Rheumatol. 2000;19:473-6.

22. Lindsey C, Brownbill RA, Bohannon RA, llich JZ. Association of physical performance measures with bone mineral density in postmenopausal women. Arch Phys Med Rehabil. 2005;86:1102-7.

23. Turner $\mathrm{CH}$. Aging and fragility of bone. J Musculoskelet Neuronal Interact. 2007;7(4):342-3.

24. Nickols-Richardson SM, Miller LE, Wootten DF, Ramp WK, Herbert WG. Concentric and eccentric isokinetic resistance training similarly increases muscular strength, fat-free soft tissue mass, and specific bone mineral measurements in young women. Osteoporos Int. 2007;8(6):789-96.

25. Stengel SV, KemmlerW, Kalender WA, Engelke K, Lauber D. Differential effects of strength versus power training on bone mineral density in postmenopausal women: a 2-year longitudinal study. Br J Sports Med. 2007;41:649-55.

26. Cardoso AS, Tartaruga LP, Barella RE, Brentano MA, Kruel LFM. Effects of a deep water training program on women's muscle strength. J Int Med Phys Ed. 2004;74:590-2.

27. Ay A, Yurtkuran M. Evaluation of hormonal response and ultrasonic changes in the heel bone by aquatic exercise in sedentary postmenopausal women. Am J Phys Med Rehabil. 2003;82:942-9.

28. Vincent KR, Braith RW. Resistance exercise and bone turnover in elderly men and women. Med Sci Sports Exerc. 2002;34(1):17-23.

29. Martyn-St James M, Carroll S. High-intensity resistance training and postmenopausal bone loss: a meta-analysis. Osteoporos Int. 2006;17(8):1225-40.

30. Kemmler W, Lauber D, Weineck J, Hensen J, Kalender W, Engelke K. Benefits of 2 years of intense exercise on bone density, physical fitness, and blood lipids in early postmenopausal osteopenic women. Arch Intern Med. 2004;164:1084-91.

31. Kessenich CR. Nonpharmacological prevention of osteoporotic fractures. Clin Interv Aging. 2007;2(2):263-6.

32. Gunendi Z, Ozyemisci-Taskiran O, Demirsoy N. The effect of 4-week aerobic exercise program on postural balance in postmenopausal women with osteoporosis. Rheumatol Int. 2008;28(12):1217-22.
33. Hourigan SR, Nitz JC, Brauer SG, O'Neill S, Wong J, Richardson CA. Positive effects of exercise on falls and fracture risk in osteopenic women. Osteoporos Int. 2008;19(7):1077-86.

34. Chan K, Qin L, Lau M, Woo J, Au S, Choy W, et al. A randomized, prospective study of the effects of Tai Chi Chun exercise on bone mineral density in postmenopausal women. Arch Phys Med Rehabil. 2004;85(5):717-22.

35. Lee MS, Pittler MH, Shin BC, Ernst E. Tai chi for osteoporosis: a systematic review. Osteoporos Int. 2008;19(2):139-46.

36. Voukelatos A, Cumming RG, Lord SR, Rissel C. A randomized, controlled trial of Tai Chi for the prevention of falls: the Central Sydney Tai Chi trial. J Am Geriatr Soc. 2007;55:1185-91.

37. Sinaki M, Mikkelsen BA. Postmenopausal spinal osteoporosis: flexion versus extension exercises. Arch Phys Med Rehabil. 1984;65(10):593-6.

38. Fukada E, Yasuda I. On the piezoelectric effect of bone. J Phys Soc Jpn. 1957;12:1158-62.

39. Adami S, Gatti D, Viapiana O, Fiore CE, Nuti R, Luisetto G, et al. Physical activity and bone turnover markers: a cross-sectional and a longitudinal study. CalcifTissue Int. 2008;83(6):388-92.

40. Rubin C, Recker R, Cullen D, Ryaby J, McCabe J, McLeod K. Prevention of postmenopausal bone loss by a low-magnitude, highfrequency mechanical stimuli: a clinical trial assessing compliance, efficacy, and safety. J Bone Miner Res. 2004;19(3):343-51.

41. Sehmisch S, Galal R, Kolios L, Tezval M, Dullin C, Zimmer S, et al. Effects of low-magnitude, high-frequency mechanical stimulation in the rat osteopenia model. Osteoporos Int. 2009. [Epub ahead of print]

42. Duarte LR. The stimulation of bone growth by ultrasound. Arch Orthop Trauma Surg. 1983;101:153-9.

43. Wu S, KawaharaY, Manabe T, Ogawa K, Matsumoto M, Sasaki A, et al. Low-intensity pulsed ultrasound accelerates osteoblast differentiation and promotes bone formation in an osteoporosis rat model. Pathobiology. 2009;76(3):99-107.

44. Lind $M$, Bunger $C$. Factors stimulating bone formation. Eur Spine J. 2001;10(Suppl 2):S102-9.

45. Busse JW, Bhandari M, Kulkarni AV, Tunks E. The effect of lowintensity pulsed ultrasound therapy on time to fracture healing: a meta-analysis. Can Med Assoc J. 2002;166:437-41.

46. Simonis RB, Parnell EJ, Ray PS, Peacock JL. Electrical treatment of tibial non-union: a prospective, randomised, double-blind trial. Injury. 2003;34(5):357-62.

47. Gan JC, Glazer PA. Electrical stimulation therapies for spinal fusions: current concepts. Eur Spine J. 2006;15(9):1301-11.

48. Lirani-Galvão APR, Bergamaschi CT, Silva OL, Lazaretti-Castro M. Electrical field stimulation improves bone mineral density in ovariectomized rats. Braz J Med Biol Res. 2006;39(11):1501-5.

49. Lirani-Galvão APR, Chavassieux P, Portero-Muzy N, Bergamaschi $\mathrm{CT}$, Silva OL, Carvalho AB, et al. Low intensity electrical stimulation counteracts the effects of ovariectomy on bone tissue of rats: effects on bone microarchitecture, viability of osteocytes and nitric oxide expression. CalcifTissue Int. 2009;84(6):502-9.

50. Chang K, Chang WH. Pulsed electromagnetic fields prevent osteoporosis in an ovariectomized female rat model: a prostaglandin E2-associated process. Bioelectromagnetics. 2003;24(3):189-98.

51. Tabrah F, Hoffmeier M, Gilbert F Jr, Batkin S, Bassett CA. Bone density changes in osteoporosis-prone women exposed to pulsed electromagnetic fields (PEMFs). J Bone Miner Res. 1990;5(5):437-42.

52. Giordano N, Battisti E, Geraci S, Fortunato M, Santacroce C, Rigato $M$, et al. Effect of electromagnetic fields on bone mineral density and biochemical markers of bone turnover in osteopo- 
rosis: a single-blind, randomized pilot study. Curr Therap Res. 2001;62(3):187-93.

53. Stein E, Koehn J, Sutter W, Wendtlandt G, Wanschitz F, Thurnher $D$, et al. Initial effects of low-level laser therapy on growth on differentiation of human osteoblast-like cells. Wien Klin Wochenschr. 2008;120:112-7.

54. Stein A, Benayahu D, Maltz L, Oron U. Low-level laser irradiation promotes proliferation and differentiation of human osteoblasts in vitro. Photomed Laser Surg. 2005;23:161-6.

55. Liu X, Lyon R, Meier HT, Thometz J, Haworth ST. Effect of lowerlevel laser therapy on rabbit tibial fracture. Photomed Laser Surg. 2007;25:487-94.
56. Renno ACM, McDoNneell PA, Parizotto NA, Laakso EL. The effects of laser irradiation on osteoblast and osteosarcoma cell proliferation on differentiation in vitro. Photomed Laser Surg. 2007;25:275-80.

57. Diniz JS, Nicolau RA, de Melo Ocarino N, do Carmo Magalhaes F, de Oliveira Pereira RD, Serakides R. Effect of low-power galliumaluminum-asenium laser therapy $(830 \mathrm{~nm})$ in combination with bisphosphonate treatment on osteopenic bone structure: an experimental animal study. Lasers Med Sci. 2009;24:347-52.

58. Lirani AP, Lazaretti-Castro M. Evidences of physical agents action on bone metabolism and their potential clinical use. Arq Bras Endocrinol Metabol. 2005;49(6):891-6. 